\title{
The Construction of oven designed by heat exchanger in drying porang at SME Coco Prima
}

\author{
Kerista Sebayang ${ }^{1 *}$, Herli Ginting ${ }^{1}$, Andriayani ${ }^{2}$, Agus Salim Harahap ${ }^{3}$ \\ ${ }^{1}$ Department of Physics, Faculty of Mathematics and Natural Sciences, Universitas Sumatera \\ Utara \\ ${ }^{2}$ Department of Chemistry, Faculty of Mathematics and Natural Sciences, Universitas Sumatera \\ Utara \\ ${ }^{3}$ Department of Mathematics, Faculty of Mathematics and Natural Sciences, Universitas \\ Sumatera Utara \\ *Email: k_sebayang@usu.ac.id
}

\begin{abstract}
The small-medium enterprise (SME) Coco Prima has been under nurtured of LPPM USU since 2018. Ever since, it has been improving its productivity and diversifying its productivity into drying products. Currently, this SME manages porang as one of new export commodity. The problem faced by partners is a large and fast drying methodology. Porang or iles-iles are rotten raw materials that only last for three days after harvesting due to the unpleasant odors resulted more than three days, and subsequently, they cannot be processed. Drying under sunlight requires to four days reaching about $70 \%$ degree of dryness. Due to unfavorable weather conditions, the raw material becomes sweaty and moldy and produces black colour and soft textures. Therefore, a $3 \times 3 \times 2$ cubic meter of drying oven has been constructed along with shelves and heat exchanges supported by liquid petroleum gas (LPG) gas. The heat exchange is designed accordingly to provide lower temperature in the oven, so that the air pressure within it is more efficient and less heat is wasted during reheating process. The heating is sufficient by using LPG and fan 18'. The oven is consisted of two layers in which between the layers are given glass wool as a heat barrier to the environment. It is also designed with a small vent exactly on the middle of the top with the intention to flow water vapour out from the vent, while the cold air is touched by that water vapour in the oven, it converts downward on the heat exchanger repeatedly. From this applied system, $750 \mathrm{~kg}$ iles-iles was heated within two days with a tube-of-12 kg LPG gas.
\end{abstract}

Keyword: Heat exchanger, oven, iles-iles, porang

\begin{abstract}
Abstrak
Sebagai hasil binaan dari tim LPPM USU 2018 UMKM Coco Prima telah mampu meningkatkan produktivitas dan juga pengembangan usaha pengeringan. Saat ini UMKM Coco Prima mengelola porang sebagai salah satu komoditas ekspor baru. Masalah yang dihadapi oleh mitra adalah metodologi pengeringan kouta besar dan cepat. Porang/iles-iles adalah bahan baku yang mudah busuk hanya bertahan tiga hari setelah panen. Bila lebih lama dari itu maka porang/iles-iles berair dan mengeluarkan bau, tidak dapat diproses lebih lanjut dan harus dibuang. Pengeringan di bawah sinar matahari membutuhkan waktu hingga empat hari untuk mencapai derajat kekeringan sekitar $70 \%$. Bila cuaca tidak mendukung atau kurang panas, bahan baku menjadi berkeringat dan berjamur, warna menjadi hitam dan lembek. Oleh karena itu telah dikonstruksi oven pengering berukuran $3 \times 3 \times 2$ meter kubik beserta dengan rak dan alat penukar panas menggunakan gas LPG. Penukar panas didesain sedemikian hingga udara dengan suhu lebih rendah dari dalam oven dipanaskan ulang sehingga lebih efisien dan panas terbuang menjadi lebih sedikit. Pemanasan cukup dengan menggunakan LPG dan kipas angin 18'. Oven terdiri dari dua lapis dimana antar lapisan diberi glass wol sebagai penahan panas dengan lingkungan. Oven diberi ventilasi kecil tepat dibagian tengah atas dengan maksud bahwa hanya uap air yang keluar dari ventilasi sedangkan udara dingin yang tersentuh uap air didalam oven kembali berkonveksi kebawah dan mengenai penukar panas. Dari hasil implementasi didapatkan pengeringan $750 \mathrm{~kg}$ iles-iles dalam waktu dua hari dengan bahan bakar LPG sebanyak 1 tabung $12 \mathrm{~kg}$.
\end{abstract}

Kata Kunci : Penukar panas, oven, iles-iles, porang 


\section{PENDAhuluan}

Proses pengeringan adalah proses yang hampir selalu dilewati oleh berbagai komoditas terutama komoditas pertanian. Proses pengeringan membutuhkan biaya dan waktu. Oleh karena itu selalu dicari metoda pengeringan yang efisien dan efektif yang dapat meminimalkan biaya dan durasi operasional. Sistem pengeringan sederhana dan tepat guna dapat diaplikasikan untuk itu. Oven perlu pelapisan penahan panas sehingga panas tidak terbuang ke lingkungan. Desain oven perlu dikembangkan agar panas tidak seluruhnya terbuang bersama dengan uap air. Penukar panas juga memerlukan desain yang dapat meloloskan volume udara yang besar dengan sentuhan permukaan bidang panas yang luas. Dari desain tersebut diharapkan proses pengeringan lebih efektif dan lebih efisien.

Usaha kecil menengah yang menjadi mitra Lembaga Pengabdian Masyarakat Universitas Sumatera Utara yaitu Coco Prima di Kota Stabat telah berkembang sebagai hasil LPM tahun sebelumnya (2018). Mitra mampu meningkatkan jumlah produksi dan melakukan pengembangan produk tidak hanya ampas kelapa kering, kopra serta tepung kelapa tetapi juga mengeringkan porang. Umbi porang/iles-iles, merupakan salah satu komoditas ekspor yang dikirim ke Cina, Jepang, Hongkong, Korea dan Eropa dan mitra mengambil bagian dalam pengolahan bahan tersebut. Bahan baku mudah didapatkan dan tersedia sangat banyak. Suplier mengantarkan bahan baku dari berbagai tempat yaitu Tanah Karo, Simalungun, Balige, Labuhan Batu, Padang dan daerah-daerah lainnya. Bahan baku yang baru datang disimpan di halaman pabrik pengolahan. Proses pengolahan dimulai dari pembersihan dan pencucian bahan baku menggunakan semprotan air dengan alat yang biasa digunakan untuk mencuci sepeda motor, dibolak-balik secara manual hingga bersih dari seluruh kotoran yang menempel. Bahan baku yang sudah bersih diangkut menuju tempat pengirisan menggunakan pengiris yang digerakkan oleh motor listrik. Selanjutnya bahan baku diangkut ketempat pengeringan berupa rak-rak yang disusun memanjang di bawah sinar matahari. Pengeringan di bawah sinar matahari ini dilakukan hingga mencapai derajat kekeringan sekitar $70 \%$, baru kemudian dimasukkan kedalam oven pengering. Bahan baku ini mengandung air hingga 86\%, dari $100 \mathrm{~kg}$ bahan baku, didapatkan bahan kering $14 \mathrm{~kg}$. Oven pengering ini menggunakan bahan bakar tandan kosong sawit. Pengeringan matahari tetap dilakukan karena jumlah oven yang tersedia tidak dapat menampung jumlah produksi yang ada. Setelah kering sempurna, produk dimasukkan kedalam goni dan dijahit, disimpan di dalam gudang menunggu kuota pengiriman terpenuhi. Mitra memiliki gudang yang dapat memuat 40 Ton produk. Tujuan pengiriman barang produksi adalah Pulau Jawa. Umumnya pembeli datang langsung memeriksa dan menyortir produk sebelum dimuat ke atas truk, dan pembayaran dilakukan tunai setelah barang diangkut oleh pembeli. Oleh pembeli, bahan baku selanjutnya diolah dan dikirim luar negeri. Mitra sering menggabungkan hasil produksi produk sejenis dari pengusaha lainnya untuk dapat memenuhi kuota pengiriman, yaitu sekitar empat kali pengiriman setiap bulan masing-masing 20 Ton. Untuk mendukung seluruh proses ini, mitra mempekerjakan sekitar 57 orang pekerja yang berasal dari masyarakat sekitar.

Masyarakat Stabat pada umumnya bergerak di bidang pertanian seperti sawit, palawija, dan tanaman keras lainnya. Mitra telah membagikan juga bibit porang kepada masyarakat sekitar dengan syarat setelah panen harus dijual kepada mitra. Kemitraan dengan masyarakat ini menggerakkan dan menumbuhkan perekonomian desa. 


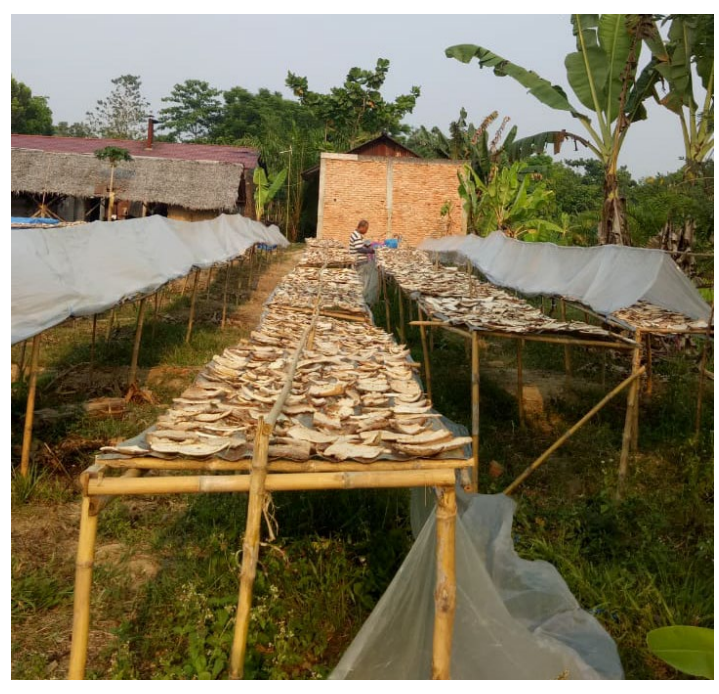

Gambar 1.1. Pengeringan Dibawah Sinar Matahari

Dari hasil kunjungan tim dari USU, obeservasi dan diskusi dengan mitra, masalah yang dihadapi mitra sekarang ini adalah penanganan poang-iles-iles yang menuntuk kecepatan. Baik karena desakan pemenuhan kouta maupun karena karakteristik porang/iles-iles itu sendiri. Porang/iles-iles adalah bahan baku yang mudah busuk hanya bertahan tiga hari setelah panen. Bila lebih lama dari itu maka porang/iles-iles berair dan mengeluarkan bau, tidak dapat diproses lebih lanjut dan harus dibuang. Pengeringan di bawah sinar matahari membutuhkan waktu hingga empat hari untuk mencapai derajat kekeringan sekitar 70\%. Bila cuaca tidak mendukung atau kurang panas, bahan baku menjadi berkeringat dan berjamur, warna menjadi hitam dan lembek. Barang seperti ini tidak memenuhi spesifikasi mutu yang disyaratkan pembeli dan dibuang pada saat penyortiran. Selain itu, bahan baku yang sudah lembek atau berjamur, lebih sulit dikeringkan lagi sekalipun menggunakan oven pengering. Keadaan ini bisa lebih parah bila bila terjadi hujan, maka kemungkinan besar bahan baku menjadi busuk.

Mitra memiliki oven pengering satu rak untuk mengeringkan bahan baku yang sudah $70 \%$ kering. Biaya operasional pengeringan ini sangat tinggi dan menjadi ancaman bagi kelangsungan produksi, rentan terhadap perubahan harga bahan pokok dan harga jual. Untuk dapat memutar blower, mitra terpaksa menggunakan generator listrik 30.000 Watt. Oven yang dimiliki mitra berbahan bakar kayu dan tandan kosong sawit, membutuhkan bahan bakar lebih dari satu truk pick-up perhari.

Hasil investigasi tim penyusul terhadap permasalahan mitra diketahui bahwa oven yang dipergunakan oleh mitra tidak menahan panas sehingga membutuhkan asupan panas terus menerus kedalam tunggu. Hal ini mengakibatkan pemakaian kayu bakar yang tinggi. Selanjutnya masalah pertukaran panas, diidentifikasi besarnya blower yang dipakai menuntut pemakaian listrik yang tinggi. Pemakaian blower yang besar ini dimaksudkan untuk mempertinggi debit udara, namun dari hasil identifikasi masalah debit udara tidak tinggi karena tekanan statis yang timbul dari desain penukar panas yang sedemikian rupa. Hal ini diperparah oleh tertutupinya permukaan penukar panas oleh jelaga dan abu, menyebabkan pertukaran panas tidak efektif. Desain penukar panas yang dipakai mitra tidak dapat dibongkar sehingga sulit dalam pembersihan dan pemeliharaan. Oven yang dimiliki mitra juga berukuran kecil hanya satu rak.

Oleh karena itu di desain penukar panas lebih efisien dengan cara pemanasan ulang udara yang bersuhu lebih dingin dan cukup dipanaskan dengan gas LPG dan udara cukup didorong dengan kipas angin tornado 18'. Model pemanasan ini cenderung meningkatkan suhu terus menerus sehingga harus dikontrol. Bila suhu yang diinginkan sudah tercapai maka mata api dari tungku stang bagian atas dapat dimatikan dan aliran udara dari kipas ditambah sehingga suhu dapat 
turun kembali. Bila suhu ingin dinaikkan kembali cukup dengan membuka keran gas maka api akan menyala sendiri.

Oven didesain sebesar $3 \times 3 \times 2$ meter kubik berinding dua lapis, antar lapisan diberi glas wol penahan hilangnya panas ke lingkungan. Ukuran oven ini memuat 10 kali lipat dari oven yang sudah ada. Bagian dalam oven dicat anti asam..

\section{METODE PELAKSANAAN}

\section{Pembuatan Unit Penukar Panas dan Oven}

Pembuatan Unit Penukar Panas dilakukan oleh pengrajin berpengalaman di kota Medan sesuai dengan rancangan yang telah dibuat. Bahan-bahan yang di perlukan seperti plat, hollow aluminium, besi-besi penyangga struktur, blower dan termometer dapat dibeli dipasar local. Perakitan dilakukan pada bengkel lokal di Kota Medan oleh pengrajin yang perlu dipantau kemajuannya oleh mitra dan pengusul secara berkala.

\section{Penyuluhan Teknologi Pengeringan} berikut:

Langkah-langkah yang akan dilakukan oleh perguruan tinggi pembina terhadap mitra sebagai

1. Memberi penjelasan hal dasar yang berpengaruh pada proses penukaran panas dan pengovenan sebagai bekal dalam operasional dan pemeliharaan.

2. Memberi penjelasan fungsi dari setiap bagian alat.

3. Memberi penjelasan bagaiamana mengoperasikan alat dengan baik, terutama hubungannya dengan suhu dan debit udara agar pertukaran panas dan pekerjaan pengeringan dapat berlangsung dengan baik.

4. Menyiapkan SOP pengoperasian alat.

5. Memperagakan bagaimana cara memelihara pengering paksa udara panas dengan baik sehingga dapat dimanfaatkan dalam jangka waktu lama.

\section{HASIL DAN PEMBAHASAN}

\section{Unit Penukar Panas}

Penukar panas telah dikonstruksi dan diujicobakan berhasil dengan baik.

\section{Unit Oven Pengeringan}

Oven pengering ukuran $3 \times 3 \times 2$ meter kubik telah selesai dikonstruksi, dinding terdiri dari dua lapis dan diisi dengan glas wol, memiliki dua pintu besar pada dua sisi yang berlawanan, lubang exhaust dibagian atas. Oven dilengkapi dengan rak pengeringan. Kapasitas pengeringan adalh $750 \mathrm{~kg}$ per batch. 

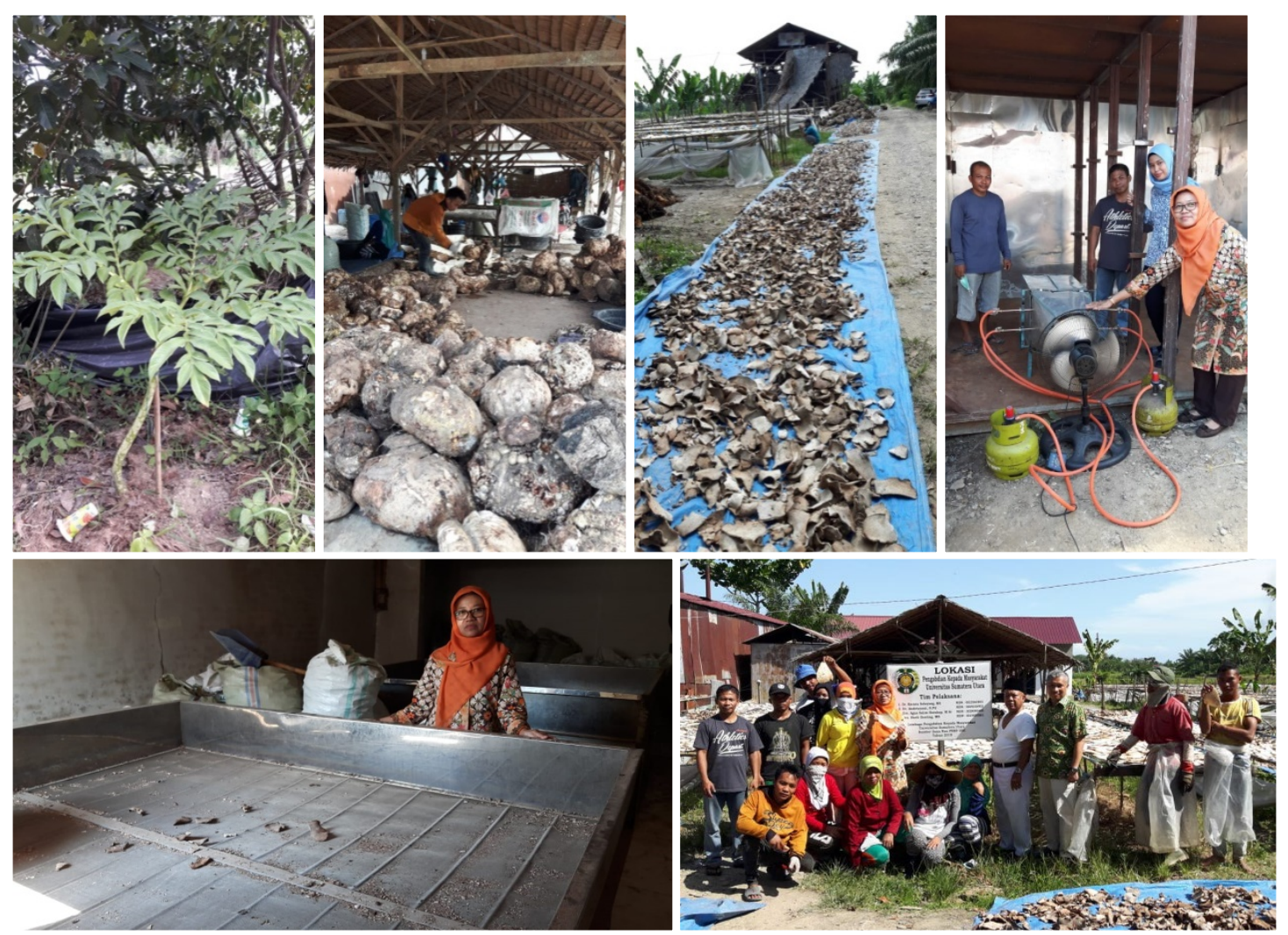

Gambar 3.1. Pengabdian Masyarakat

\section{KESIMPULAN}

Telah dikonstruksi penukar panas efisien dan oven pengeringan untuk dapat mengatasi permasalahan mitra.

\section{UCAPAN TERIMAKASIH}

Pengabdian Kepada Masyarakat dibiayai oleh NON PNBP USU sesuai Kontrak Pelaksanaan Pengabdian Kepada Masyarakat, Program Multi Tahun, Tahun Anggaran 2019 Nomor: 327/UN5.2.3.2.1/PPM/2019 Tanggal 20 Mei 2019.

\section{DAFTAR PUSTAKA}

Misha, Suhaimi \& Sohif, Mat \& Ruslan, M.H. \& Sopian, Kamaruzzaman \& Salleh, Elias. (2013). Review on the Application of a Tray Dryer System for Agricultural Products. World Applied Sciences Journal. 22. 424-433. 10.5829/idosi.wasj.2013.22.03.343.

Park H W, Yoon W B. Effects of air movement in a hot air dryer on the drying characteristics of colored potato (Solanum tuberosum L.) using computational fluid dynamics. Int J Agric \& Biol Eng, 2018; 11(1): 232-240.

T.N. Valarmathi1, S. Sekar2, M. Purushothaman3, S.D. Sekar4, Maddela Rama Sharath Reddy5 and Kancham Reddy Naveen Kumar Reddy, 2017, IOP Conf. Ser.: Mater. Sci. Eng. 197 012037 
ISSN Printed Version: 2549-4341

Kerista Sebayang et.al. The Construction of Oven

Xiang dong Xu, Xingjuan Zhang, Peng Ke, Chao Wang, Han Yang, Chunxin Yanga, 2015, Study on the Heat Transfer Characteristic of Compact Heat Exchanger Based on Experimental Data, Procedia Engineering 121 (2015) 293 - 299 